Article

\title{
Study on Optimum IUPAC Adsorption Isotherm Models Employing Sensitivity of Parameters for Rigorous Adsorption System Performance Evaluation
}

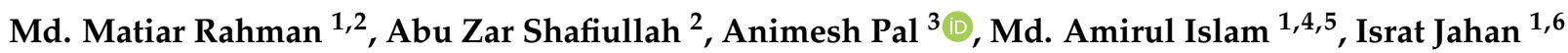 \\ and Bidyut Baran Saha $1,6, *$ (D)
}

1 International Institute for Carbon-Neutral Energy Research (WPI-I2CNER), Kyushu University, 744 Motooka, Nishi-ku, Fukuoka 819-0395, Japan; matiar@du.ac.bd (M.M.R.); islam.md.amirul.240@m.kyushu-u.ac.jp (M.A.I.); nazli81012@gmail.com (I.J.)

2 Department of Statistics, University of Dhaka, Dhaka 1000, Bangladesh; shafi.ullah@du.ac.bd

3 Department of Nuclear Engineering, University of Dhaka, Dhaka 1000, Bangladesh; animeshpal@du.ac.bd

4 Institute for Materials Chemistry and Engineering, Kyushu University, Kasuga-koen 6-1, Kasuga-shi 816-8580, Japan

5 Department of Electronics and Telecommunication Engineering, Bangabandhu Sheikh Mujibur Rahman Science \& Technology University, Gopalganj 8100, Bangladesh

6 Mechanical Engineering Department, Kyushu University, 744 Motooka, Nishi-ku, Fukuoka 819-0395, Japan

* Correspondence: saha.baran.bidyut.213@m.kyushu-u.ac.jp

\section{check for} updates

Citation: Rahman, M.M.; Shafiullah, A.Z.; Pal, A.; Islam, M.A.; Jahan, I.; Saha, B.B. Study on Optimum IUPAC Adsorption Isotherm Models Employing Sensitivity of Parameters for Rigorous Adsorption System Performance Evaluation. Energies 2021, 14, 7478. https://doi.org/ $10.3390 /$ en14227478

Academic Editors: Issa Chaer and Jaroslaw Krzywanski

Received: 15 September 2021 Accepted: 1 November 2021 Published: 9 November 2021

Publisher's Note: MDPI stays neutral with regard to jurisdictional claims in published maps and institutional affiliations.

Copyright: (c) 2021 by the authors Licensee MDPI, Basel, Switzerland. This article is an open access article distributed under the terms and conditions of the Creative Commons Attribution (CC BY) license (https:// creativecommons.org/licenses/by/ $4.0 /)$.

\begin{abstract}
Adsorption cooling technologies driven by low-grade thermal or solar power are used as an energy-efficient alternative to conventional refrigeration and air conditioning systems. Explicit understanding of the adsorption cycles requires precise determination of the performance parameters, replication of the experimental data, and the rigorous study of the adsorption heat transformation method. Hence, the optimum adsorption isotherms model must be identified. Scientists often face difficulties in selecting the suitable isotherm model as there are many models for a particular form of adsorption isotherm. The present study introduces a novel approach for choosing the optimal models for each type of International Union of Pure and Applied Chemistry (IUPAC) classified adsorption isotherm using robust statistical methods. First, the box-and-whisker plots of error identification are employed. Tóth for Type-I(a) and Type-I(b), modified BET for Type-II, GAB for Type-III, Universal for Type-IV(a), and Type-IV(b), Sun Chakrabarty for Type-V, and Yahia et al. for Type-VI were found lower than the other candidate models in box-and-whisker plot. The optimality of our selected models was further verified using analysis of variance (ANOVA), pairwise Tukey honest significant difference (HSD) test, Kruskal-Wallis rank-sum test, and pairwise Wilcoxon rank-sum test. In short, rigorous statistical analysis was performed to identify the best model for each type of isotherm by minimizing error. Moreover, specific cooling effect (SCE) of Maxsorb III/ethanol and silica gel/water pairs were determined. Results showed that Tóth is the optimal isotherm model for the studied pairs, and the SCE values obtained from the model agree well with experimental data. The optimum isotherm model is indispensable for the precise designing of the next generation adsorption cooling cycles.
\end{abstract}

Keywords: ANOVA; IUPAC; optimum isotherm; statistical analysis; Tukey HSD

\section{Introduction}

Thermally driven cooling technologies are receiving a lot of interest from scientists as a way to minimize world electricity demand. Adsorption-based cooling systems, which can be powered by low-grade thermal energy, have been shown to be particularly successful in this regard. Waste heat [1-3] or heat from cost-effective no-concentrating solar thermal collectors [4-7] can be used for this reason. An adsorbent bed, a heat exchanger in which the adsorbent materials are kept, is one of the most important components of an adsorption 
refrigeration system. The beds go through adsorption and desorption activities in the adsorption cycles to produce thermal compression of the refrigerant vapor [8].

Adsorption/desorption isotherms are obtained at various adsorption temperatures by varying the pressure of the adsorbate. The highest amount of adsorbate which can be absorbed by the adsorbent at a given pressure is determined by these isotherms. Moreover, different adsorbent/adsorbate pairs show different isotherm shapes, and often a hysteresis is also observed. It is essential to relate experimental data from various adsorption pairs with different isotherm models in order to reproduce them. The International Union of Pure and Applied Chemistry (IUPAC) [9] defines adsorption isotherms into eight categories depending on their nature, as shown in Figure 1. In general, isotherm data are correlated using a variety of isotherm models, with the best-fitted model being used to examine adsorption characteristics. Rocky et al. [10] recently developed a zeolite-graphene composite for next-generation adsorption heat pump systems. They examined water adsorption onto these composites and used three isotherms to correlate the experimental data: modified Langmuir, Sun and Chakrabarty, and Universal model. Jahan et al. [11] used an energy-efficient, environmentally friendly, fast, and ultrasonication-assisted room temperature technique to synthesize MOF-801. For water adsorption onto MOF-801, the Sun and Chakrabarty, D-A, and Universal models were utilized. According to the literature, various pairs exhibit different adsorption isotherms, and multiple scholars have attempted to discover the best model for these types [12].

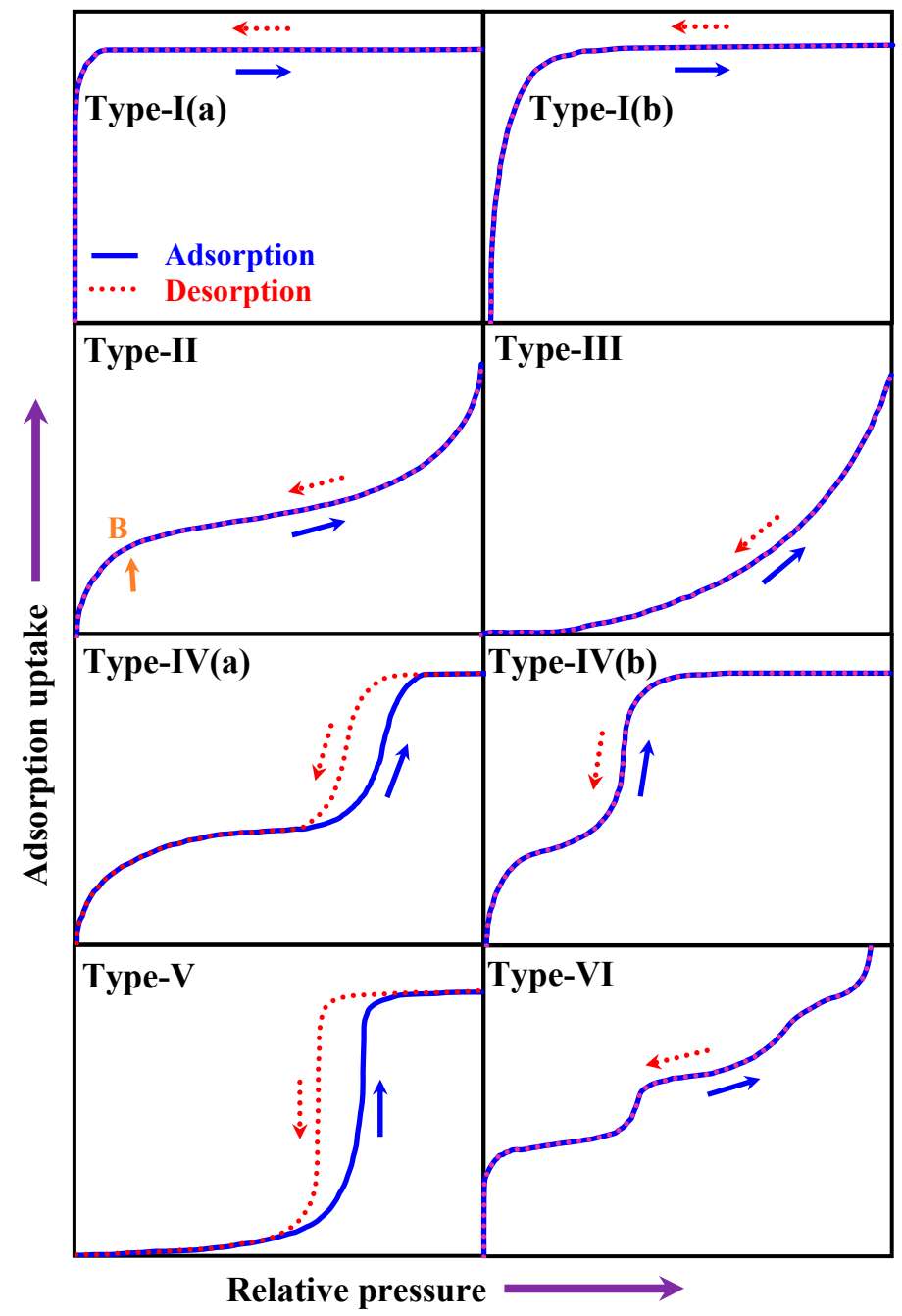

Figure 1. Types of adsorption isotherms [9,12]. (Reproduced with permission). 
The optimum models for IUPAC classified isotherms were identified using a statistical approach [12]. The parameters of the models were determined by applying the generalized reduced gradient (GRG) technique. The GRG approach fits the candidate models by visualizing the fitted graph, which minimizes the root mean square error deviation (RMSD). However, the procedure relies on graphical tuning for optimum solutions. Thus, the results are subjective and often vary from one experimenter to another. Moreover, during optimization, if the estimate of a parameter deviates substantially, it may affect the results for the remaining parameters. Thus, the sensitivity or deviation in the parameter estimates should be considered while selecting the best model. The previous study [12] further applied the information-based criteria to identify the best model. The commonly used information criteria often select the complex model, i.e., the model which contains a relatively large number of parameters. Thus, the subjective choice of the parameter estimates in the GRG approach may affect the candidate models differently. This paper addresses these issues by considering simulation-based sensitivity analysis of the candidate models. Therefore, this study improves the previous work by examining the effect of random variation in the choice of estimates for the models.

A data set of adsorbent-adsorbate pairs is analyzed for each type of IUPAC classified isotherms in this study. Assuming that the estimated parameters [12] are close proximities to the actual values, the simulated estimates are obtained from the multivariate normal distribution for each candidate model. The current work aims to find the best isotherm models for all types of IUPAC classified isotherms, which was achieved by:

(i) Examining the isotherm models and statistical methodologies.

(ii) The model parameters have been optimized employing the generalized reduced gradient (GRG) non-linear optimization technique.

(iii) The optimized parameters are varied deliberately within a small range of a large number $(\mathrm{N}=10,000)$ of times to generate the empirical distributions of the RMSD.

(iv) Box-and-whisker plots have been constructed of all candidate models for all types of IUPAC isotherms.

(v) The parametric method ANOVA and Tukey HSD tests, as well as non-parametric method Kruskal-Wallis and Wilcoxon rank-sum tests, have been applied to find the significantly optimum models by minimizing RMSD.

(vi) The robustness has been confirmed by determining the specific cooling effect (SCE) of Maxsorb III/ethanol and silica gel/water pairs.

\section{Adsorption Isotherm Models}

The adsorption isotherm model can explain the equilibrium uptake at a specific temperature for a certain adsorbent-adsorbate pair [13]. The researchers suggested various isotherm models to replicate the experimental data of different adsorption pairs. Table 1 presents the models considered in this study.

Table 1. Non-linear adsorption isotherms models, parameters, and references.

\begin{tabular}{|c|c|c|c|}
\hline Isotherm & Nonlinear Form & Parameters & Reference \\
\hline Freundlich & $\frac{W}{W_{0}}=\left(\frac{P}{P_{s}}\right)^{\frac{1}{n}}$ & $W_{0}, n$ & [14-16] \\
\hline Langmuir & $\frac{W}{W_{0}}=\frac{b_{0} e^{\frac{Q}{R T} P}}{1+b_{0} e^{\frac{Q}{R T} P}}$ & $W_{0}, Q, b_{0}$ & [17-20] \\
\hline D-A & $\frac{W}{W_{0}}=\exp \left[-\left\{\frac{R T}{E} \ln \left(\frac{P_{s}}{P}\right)\right\}^{n}\right]$ & $W_{0}, E, n$ & {$[21,22]$} \\
\hline Mod. (D-A) & $\begin{array}{c}q_{a b s}^{*}=\frac{W_{0}}{V_{m}} \exp \left[-\left\{\frac{R T}{E} \ln \left(\frac{P_{s}}{P}\right)\right\}^{n}\right] \text { where, } \\
V_{m}=V_{t} \exp \left[\alpha\left(T-T_{t}\right)\right] \text { and } P_{s}=\left(\frac{T}{T_{c}}\right)^{k} P_{c}\end{array}$ & $W_{0}, E, n, K$ & {$[23,24]$} \\
\hline
\end{tabular}


Table 1. Cont.

\begin{tabular}{|c|c|c|c|}
\hline Isotherm & Nonlinear Form & Parameters & Reference \\
\hline Tóth & $\frac{W}{W_{0}}=\frac{b_{0} e \frac{Q}{R T} P}{1+b_{0} e \frac{Q}{R T} P}$ & $W_{0}, b_{0}, Q, t$ & [25-27] \\
\hline Hill & $\frac{W}{W_{0}}=\frac{\left(\frac{P}{P_{S}}\right)^{n_{H}}}{K_{D}+\left(\frac{P}{P_{s}}\right)^{n_{H}}}$ & $W_{0}, n_{H}, K_{D}$ & {$[16,28,29]$} \\
\hline Mahle & $\begin{array}{c}\frac{W}{W_{s}}=\frac{1}{C}\left[\tan ^{-1}\left(\frac{x-A}{B}\right)-\tan ^{-1}\left(\frac{-A}{B}\right)\right] ; \text { where, } \\
C=\tan ^{-1}\left(\frac{1-A}{B}\right)-\tan ^{-1}\left(\frac{-A}{B}\right) \text { and } \\
A=\exp \left(A_{0}+\frac{A_{1}}{T}\right)\end{array}$ & $W_{s}, A_{0}, A_{1}, B$ & [30] \\
\hline BET & $\frac{V}{V_{m}}=\frac{C x}{(1-x)(1-x+C x)} ;$ and $x=\frac{P}{P_{0}}$ & $V_{m}, C$ & {$[17,31]$} \\
\hline Modified BET & $\frac{V}{V_{m}}=\frac{C K x}{(1-K x)\{(1+(C-1) K x)\}}$ & $V_{m}, C, K$ & {$[12,17]$} \\
\hline GAB & $\begin{array}{c}\quad V \\
V_{m}=\frac{C K x}{(1-K x)\{1+(C-1) K x\}} ; \text { where, } \\
C=C_{0} \exp \left(\frac{\Delta H_{1}}{R T}\right) ; K=K_{0} \exp \left(\frac{\Delta H_{2}}{R T}\right) ; \\
\Delta H_{1}=H_{m}-H_{n} \text { and } \Delta H_{2}=H_{1}-H_{n}\end{array}$ & $\begin{array}{c}V_{m}, C_{0}, K_{0}, \Delta H_{1} \text { and } \\
\Delta H_{2}\end{array}$ & {$[32,33]$} \\
\hline Mod. Langmuir & $\begin{array}{c}\frac{W}{W_{0}}=\frac{\beta\left(\frac{P}{\varphi^{*}}\right)}{\left[1+\left(\beta^{m}-\alpha\right)\left(\frac{P}{\varphi^{*}}\right)^{m}\right]^{\frac{1}{m}}} ; \text { Where, } \\
\frac{P}{\varphi^{*}}=\left(\frac{P}{P_{s}}\right) \exp \left\{\frac{\phi_{m}}{R T}\left\{1-\left(\frac{P}{P_{s}}\right)^{n}\right\}+z\right\}\end{array}$ & $\begin{array}{l}W_{0}, z, \beta, \alpha, n_{1} \\
\quad \phi_{m}, m\end{array}$ & {$[34,35]$} \\
\hline Sun and Chakraborty & $\begin{aligned} \frac{W}{W_{0}} & =\frac{K\left(\frac{P}{P_{s}}\right)^{m}}{1+(K-1)\left(\frac{P}{P_{s}}\right)^{m}} ; \text { Where, } \\
K & =\alpha \exp \left[\frac{m\left(Q_{s t}^{*}-h_{f g}\right)}{R T}\right]\end{aligned}$ & $W_{0}, Q_{s t}{ }^{*}, m, \alpha$ & {$[11,34,36]$} \\
\hline Ben Yahia & $\begin{aligned} W= & \frac{n_{1} N_{M 1}\left(\frac{P}{P_{1}}\right)^{n_{1}}}{1+\left(\frac{P}{P_{1}}\right)^{n^{1}}}+\frac{n_{2} N_{M 2}\left(\frac{P}{P_{2}}\right)^{n_{2}}}{1+\left(\frac{P}{P_{2}}\right)^{n^{2}}}+\frac{n_{3} N_{M 3}\left(\frac{P}{P_{3}}\right)^{n_{3}}}{1+\left(\frac{P}{P_{3}}\right)^{n^{3}}}+ \\
& \frac{n_{4} N_{M 4}\left(\frac{P}{P_{4}}\right)^{n_{4}}}{1+\left(\frac{P}{P_{4}}\right)^{n^{4}}} ; \text { and } P_{i}=P_{S} \exp \left(\frac{E_{a i}}{R T}\right)\end{aligned}$ & $\begin{array}{l}n_{1}, n_{2}, n_{3}, n_{4}, N_{M 1}, N_{M 2} \\
N_{M 3}, N_{M 4}, P_{1}, P_{2}, P_{3}, P_{4}\end{array}$ & {$[37,38]$} \\
\hline Universal & $\begin{aligned} & \frac{q}{q *}=\sum_{i=1}^{n} \alpha_{i} {\left[\frac{\left(\frac{p}{p_{s}} \exp \left(\frac{\varepsilon_{o i}}{R T}\right)\right)^{\frac{R T}{m i}}}{1+\left(\frac{p}{p_{s}} \exp \left(\frac{\varepsilon_{o i}}{R T}\right)\right)^{\frac{R T}{m i}}}\right] ; \text { Where, } } \\
& \alpha_{1}+\alpha_{2}+\alpha_{3}+\alpha_{4}=1\end{aligned}$ & $q^{*}, \alpha_{i}, \varepsilon_{o i}, m_{i}$ & {$[13,39]$} \\
\hline
\end{tabular}

\section{Error Evaluation Function}

In this study, root mean square error deviation (RMSD) functions are adopted to optimize model parameters. Researchers often use this RMSD [21,40] error function, which can be expressed as:

$$
\mathrm{RMSD}=\sqrt{\frac{\sum_{i=1}^{n}\left(W_{\text {exp }}-W_{\text {cal }}\right)_{i}^{2}}{n}}
$$

Here $W_{\text {exp }}$ and $W_{\text {cal }}$ represent experimental uptake and model uptake, respectively and $n$ is the number of observations. RMSD error function can be used to determine model parameters that consider a large irregular error.

\section{Simulation Approach}

The parameters of the candidate models are estimated graphically using the GRG non-linear optimization technique in Excel. Thus, the best choice for the estimates is often subjective and may deviate with a measurement error in case different researchers analyze the same data or slightly different data are obtained even though the experiment is repeated under the same condition. 
Since conducting experiments are time-consuming and highly expensive, it is not feasible to replicate the experiments many times and capture the variation in the estimates of model parameters. As a result, we cannot examine directly how the subjective choice or measurement error results in biased estimates of parameters. In other words, the effect of experimental variability on the variation of parameter estimates from the GRG approach cannot be assessed. Thus, the prediction of experimental outcomes by the different candidate models may be affected by the bias due to measurement error. This study examines the effect empirically, i.e., by adopting a simulation-based comparison of RSMD of the candidate models. The simulation approach randomly changes the estimates of model parameters proposed in [12] and is assumed to be reliable. For a given model, the deviation from the estimates $\hat{\theta}$ of [12] takes place deliberately by (i) generating random samples from a multivariate normal distribution with mean vector equals the vector of estimates $\hat{\theta}$ or (ii) adding to the estimates a randomly selected sample from $N(0,1)$ as the measurement error terms for the GRG method.

Thus, the above procedure results from a set of RSMD for the candidate models attributed to the measurement error or bias due to subjective choice of parameter estimates from the graphs. We perform the simulation approach a large number of times and compare the prediction performance of the models based on the empirical distribution of RSMD.

Given a set of parameters $\theta=\left(\theta_{1}, \theta_{2}, \cdots, \theta_{p}\right)$ with the proposed estimates $\hat{\theta}=$ $\left(\hat{\theta}_{1}, \hat{\theta}_{2}, \cdots, \hat{\theta}_{p}\right)$, which are assumed to have minimum prediction error, the procedure (i) can be stated as follows.

(a) Randomly select a vector from $x=\left(x_{1}, x_{2}, \cdots, x_{p}\right)$ from a multivariate normal distribution with mean vector $\hat{\theta}$ and variance-covariance matrix $\Sigma$. We assume that the variances are small $(0.01,0.001$, etc.), i.e., the variability in the choice of estimates from the GRG graph is not substantial.

(b) Obtain the predicted values of the experimental outcomes by using the selected estimates and compute the corresponding RMSD's.

(c) Repeat (a) and (b) a large number $(10,000)$ of times and compare the prediction performance of the models based on the empirical distributions of the RSMD's.

Unlike (i), (ii) assumes that the random (measurement) errors or bias terms follow a normal distribution. Thus, the procedure is different from (i) in that the simulated estimates in (a) are obtained by randomly generating a sample from $\mathrm{N}(0,1)$ and adding to $\hat{\theta}$.

We adopt the simulation-based approaches and compare the results for each model in Table 1. Thus, the sensitivity of the models is examined under the condition where the parameter estimates are slightly biased due to the subjective judgment of the experimenters using the graphical GRG technique.

\section{Statistical Tools}

\subsection{The Box-and-Whisker Plot}

The box-and-whisker plot [41] is a chart comprising five concise statistics, which are the smallest (min), 1st quartile $\left(Q_{1}\right)$, 2nd quartile $\left(M_{e}\right)$, 3rd quartile $\left(Q_{3}\right)$, and the maximum (max) value of a data set. In this plot, a box is drawn from the first quartile $\left(Q_{1}\right)$ to the third quartile $\left(Q_{3}\right)$. Median $(M e)$ is a perpendicular line that goes between $Q_{1}$ and $Q_{3}$. The whiskers are a line from $Q_{1}$ to minimum and $Q_{3}$ to the maximum. This plot divides the total number of observations into four groups, as shown in Figure 2.

\subsection{Analysis of Variance (ANOVA)}

The statistician Ronald Fisher developed ANOVA [41,42]. In ANOVA, the total variation in a data set is divided into different influential factors known as sources of variation. ANOVA provides a test for equality of several means (F-test), a generalization of $t$-test for more than two means. The null hypothesis is given by-

Hypothesis $\mathbf{H}_{0}: \mu_{1}=\mu_{2}=\mu_{3} \ldots=\mu_{k} v$ s. 
Hypothesis $\mathbf{H}_{1}$ : At least two means are unequal.

Where $k$ indicates the number of independent groups for comparison.

The test statistic is given by, $F=\frac{M S_{\text {Bet }}}{M S_{\text {With }}}$; where, $M S_{\text {Bet }}=\frac{S S_{\text {Bet }}}{K-1}$ and $M S_{\text {With }}=\frac{S S_{\text {With }}}{N-k}$. $M S_{B e t}$ indicates between the mean sum of squares and $M S_{\text {With }}$ measures within the mean sum of squares of the candidate models. $N$ indicates the number of observations, and $K$ defines the number of candidate models in each type.

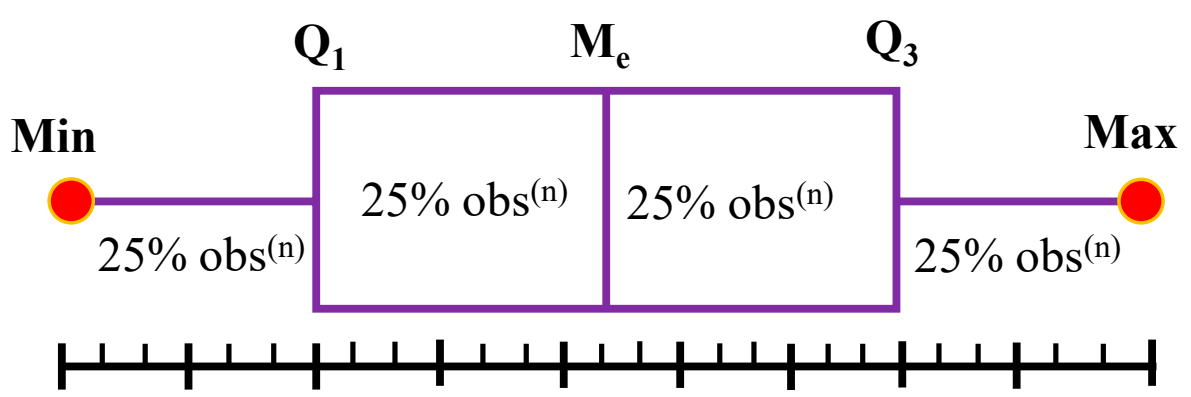

Figure 2. The box-and-whisker plot.

\subsection{Pairwise Test (Tukey's HSD Test)}

Tukey's test (HSD test) [43] can be used to determine whether two means are significantly different or not. Dunnett's and Scheffe's tests are two further multiple comparison tests. We might compare the two group means using a $t$-test with only two different groups of observations. Because of the issue of multiple comparisons, it is incorrect to compare each pair using a $t$-test when there are more than two groups. The proper way to carry out the study is to employ a one-way ANOVA to see if there is any evidence that the population means differ. If the ANOVA reveals that the group means differ, we may want to look into which of the means is different. The Tukey HSD test is applied in this case. Tukey's test is a multiple comparison test that can be used when comparing more than two means. Tukey's HSD test is usually used after the ANOVA F-test to determine which pairs of means are substantially different. The HSD can be calculated using the following formula-

$$
H S D=q \sqrt{\frac{M S}{n}}
$$

MS stands for mean square value, $n$ for the number of observations in each group, and the Studentized range distribution table provides the value for $q$. The information can be found in D.G. Altman's book named "Practical Statistics for Medical Research" (1995) [44].

\subsection{Non-Parametric Method}

The population distribution or sample size are not specified in a non-parametric technique [45]. Most parametric approaches, on the other hand, assume quantitative data, a normal population, and a suitably high sample size. Non-parametric inferences are less powerful than parametric findings in general. However, non-parametric approaches are robust, flexible, and suitable to non-quantitative data since they make fewer assumptions. In this study, the non-parametric methods are considered to validate the results from parametric methods.

\subsection{Kruskal-Wallis Rank-Sum Test}

The generalization of a rank-sum test when the number of groups $l \geq 2$ is known as the Kruskal-Wallis test [46]. It is also known as the Kruskal-Wallis H-test. Here, the normality assumption of the population like ANOVA is not considered. The null hypothesis of this test is-

Hypothesis $\mathbf{H}_{\mathbf{0}}$ : All sample/groups come from the same population, vs. 
Hypothesis $\mathbf{H}_{\mathbf{1}}$ : They come from different populations.

The test statistic is- $h=\frac{12}{n(n+1)} \sum_{i=1}^{l} \frac{r_{i}^{2}}{n_{i}}-3(n+1)$, here, $r_{i}$ is the sum of ranks of $i$ th group, $n=n_{1}+n_{2}+n_{3}+\ldots \ldots+n_{l}$ is the total number of observations, and $h$ is distributed as chi-square distribution with (l-1) degrees of freedom.

\subsection{Wilcoxon Rank-Sum Test with Continuity Correction}

Wilcoxon rank-sum [47] test is appropriate for two samples $t$-test where the population distribution is not normal. The null hypothesis is $H_{0}: \mu_{1}=\mu_{2}$ against $H_{1}: \mu_{1} \neq \mu_{2}$ or $H_{1}: \mu_{1} \geq \mu_{2}$ or $H_{1}: \mu_{1} \leq \mu_{2}$. The test statistic (normal approximation) is given by$N=n_{1}+n_{2} z=\frac{W-n_{1}(N+1) / 2}{\sqrt{n_{1} n_{2}(N+1) / 12}}$ is normally distributed with mean zero and variance one. Where $N=n_{1}+n_{2}$ and $W$ indicates the sum of ranks of the first sample.

\section{Specific Cooling Effect}

A significant performance parameter that can be measured using the equation below is the specific cooling effect (SCE) [24,48].

$$
\mathrm{SCE}=\left(W_{\max }-W_{\min }\right)\left[\Delta h_{e v a}-\int_{T_{e}}^{T_{c}} C_{p_{r e f}} d t\right]
$$

$W_{\max }$ indicates the maximum uptake, and $W_{\min }$ means the minimum uptake. The enthalpy of vaporization is represented by $\Delta h_{\text {eva }}$, and $C_{\text {pref }}$ is the refrigerant specific heat. $W_{\max }$ and $W_{\min }$ can be determined in the following equations: (Considering D-A equation (say)).

$$
W_{\max }=W_{0} \exp \left[-\left\{\frac{R T_{\text {adsorption }}}{E} \ln \left(\frac{P_{\text {adsorption }}}{P_{\text {evaporating }}}\right)\right\}^{n}\right]
$$

where $W_{0}$ indicates the highest uptake $\left(\mathrm{kg} \mathrm{kg}^{-1}\right), R$ universal gas constant $\left(\mathrm{J} \mathrm{mol}^{-1} \mathrm{k}^{-1}\right)$, $E$ is the adsorption characteristic parameter $\left(\mathrm{J} \mathrm{mol}^{-1}\right)$. $T_{\text {adsorption }}, P_{\text {adsorption }}$ and $P_{\text {evaporating }}$ measure adsorption temperature, adsorption pressure, and measures evaporating pressure, respectively.

$$
W_{\text {min }}=W_{0} \exp \left[-\left\{\frac{R T_{\text {desorption }}}{E} \ln \left(\frac{P_{\text {desorption }}}{P_{\text {condensation }}}\right)\right\}^{n}\right]
$$

Here, $T_{\text {desorption }}, P_{\text {desorption }}$, and $P_{\text {condensation }}$ denote desorption temperature, desorption pressure, and condensation pressure, respectively.

\section{Results and Discussion}

One relevant adsorption pair data is considered for each of the IUPAC types. A GRG non-linear optimization method has been used to optimize the model's parameters using the RMSD error evaluation function. The adsorption isotherm pairs of K4-700/ $\mathrm{N}_{2}$, Maxsorb III/ethanol, Alumina/Water, dried raisins/moisture, PVDC/water, IRMOF-74-Vhex/Argon, FAM-Z01/water, MgO/methane have been considered for Type-I(a), Type-I(b), Type-II, Type-III, Type-IV(a), Type-IV(b), Type-V and Type-VI, respectively. GRG nonlinear optimization approach was used to estimate the parameters. Table 2 shows the estimated parameters of the probable isotherm models for each type. Descriptive statistics, boxand-whisker plot for each type of isotherm, were constructed using $N=10,000$ simulated sample. The optimum models are confirmed by using robust statistical tests, ANOVA, Tukey HSD, and non-parametric Kruskal-Wallis rank-sum test, and Wilcoxon rank-sum test with continuity correction.

In the present study, $n=10,000$ samples have been taken by varying parameters using the multivariate normal distribution, and for each case, errors have been calculated. The box-and-whisker plot was constructed using this error distribution and presented in Figure 3. 
Table 2. Fitting parameters of the candidate models for Type-I(b) adsorption isotherm.

\begin{tabular}{|c|c|}
\hline \multicolumn{2}{|r|}{ Type-I(a) (Carbon $\mathrm{K} 4-700 / \mathrm{N}_{2}$ pair at $\left.77 \mathrm{~K}\right)$} \\
\hline Model & Parameters \\
\hline Mahle & $\mathrm{W}_{0}=0.62, \mathrm{~A}_{0}=0.045, \mathrm{~A}_{1}=-720, \mathrm{~B}=0.01$ \\
\hline Universal & $\mathrm{W}_{0}=0.709, \varepsilon_{01}=4120, \varepsilon_{02}=0.0345, \mathrm{~m}_{1}=320, \mathrm{~m}_{2}=1000, \alpha_{1}=0.71, \alpha_{2}=0.29$ \\
\hline $\mathrm{D}-\mathrm{A}$ & $\mathrm{W}_{0}=0.607, \mathrm{E}=320, \mathrm{n}=3.31$ \\
\hline Tóth & $\mathrm{W}_{0}=0.61, \mathrm{~b}_{0}=9.79 \times 10^{-5}, \mathrm{Q}=6013.84, \mathrm{t}=1.3$ \\
\hline Mod BET & $\mathrm{V}_{\mathrm{m}}=0.594, \mathrm{C}=5334.78, \mathrm{k}=0.0446$ \\
\hline \multicolumn{2}{|r|}{ Type-I(b) (Maxsorb III/ethanol) } \\
\hline Freundlich & $\mathrm{W}_{0}=1.482082, \mathrm{n}=2.214175$ \\
\hline Langmuir & $\mathrm{W}_{0}=1.38, \mathrm{~b}_{0}=3.10 \times 10^{-9}, \mathrm{Q}=48,600$ \\
\hline $\mathrm{D}-\mathrm{A}$ & $\mathrm{W}_{0}=1.17, \mathrm{E}=143.00, \mathrm{n}=1.9$ \\
\hline Tóth & $\mathrm{W}_{0}=1.2, \mathrm{~b}_{0}=3.10 \times 10^{-9}, \mathrm{Q}=47,635, \mathrm{t}=1.69$ \\
\hline Hill & $\mathrm{W}_{0}=1.266, \mathrm{n}_{\mathrm{h}}=1.321, \mathrm{~K}_{\mathrm{D}}=0.080297$ \\
\hline \multicolumn{2}{|r|}{ Type-II (Alumina/water) } \\
\hline Mod BET & $\mathrm{V}_{\mathrm{m}}=0.21, \mathrm{C}=25.5, \mathrm{k}=0.8186$ \\
\hline Universal & $\mathrm{W}_{0}=1.22, \varepsilon_{01}=217.88, \varepsilon_{02}=0.1762 .69, \mathrm{~m}_{1}=262.59, \mathrm{~m}_{2}=3231.58, \alpha_{1}=0.42, \alpha_{2}=0.57$ \\
\hline $\mathrm{D}-\mathrm{A}$ & $\mathrm{W}_{0}=1.068, \mathrm{E}=73.72, \mathrm{n}=0.504$ \\
\hline Tóth & $\mathrm{W}_{0}=1.23, \mathrm{~b}_{0}=2.32 \times 10^{-3}, \mathrm{Q}=16,932.30, \mathrm{t}=0.4165$ \\
\hline Langmuir & $\mathrm{W}_{0}=0.891, \mathrm{~b}_{0}=3.69 \times 10^{-5}, \mathrm{Q}=24,041.91$ \\
\hline \multicolumn{2}{|r|}{ Type-III (Dried raisins/moisture) } \\
\hline GAB & $\mathrm{V}_{\mathrm{m}}=10.517, \mathrm{C}_{0}=0.0011, \mathrm{~K}_{0}=1.767, \Delta \mathrm{H}_{1}=18.25, \Delta \mathrm{H}_{2}=-1.47$ \\
\hline Mod BET & $\mathrm{V}_{\mathrm{m}}=10.421, \mathrm{C}=1.47, \mathrm{k}=0.980$ \\
\hline Universal & $\mathrm{W}_{0}=120, \varepsilon_{01}=547.67, \varepsilon_{02}=120.12, \mathrm{~m}_{1}=199.95, \mathrm{~m}_{2}=1846.68, \alpha_{1}=0.65, \alpha_{2}=0.35$ \\
\hline Mod Langmuir & $\mathrm{W}_{0}=90.24, \mathrm{z}=0.1416, \beta=0.0859, \alpha=0.958, \mathrm{n}_{1}=0.95, \phi_{\mathrm{m}}=3.22, \mathrm{~m}=0.7632$ \\
\hline Sun and Chakrabarty & $\mathrm{W}_{0}=93.3581, \mathrm{Q}_{\mathrm{st}}{ }^{*}=3166.83, \mathrm{~m}=2.449, \alpha=1.81 \times 10^{-6}$ \\
\hline \multicolumn{2}{|r|}{ Type-IV(a) (PVDC/water) } \\
\hline Universal & $\mathrm{W}_{0}=0.36, \varepsilon_{01}=2096.47, \varepsilon_{02}=5613.18, \mathrm{~m}_{1}=478.42, \mathrm{~m}_{2}=4025.91, \alpha_{1}=0.67, \alpha_{2}=0.33$ \\
\hline Ben Yahia & $\mathrm{n}_{1}=1.30, \mathrm{n}_{2}=0.13, \mathrm{n}_{3}=0.032, \mathrm{n}_{4}=1.3, \mathrm{~N}_{\mathrm{M} 1}=0.123, \mathrm{~N}_{\mathrm{M} 2}=0.150, \mathrm{~N}_{\mathrm{M} 3}=0.495, \mathrm{~N}_{\mathrm{M} 4}=0.399$ \\
\hline Mod BET & $\mathrm{V}_{\mathrm{m}}=1.0533, \mathrm{C}=453.92, \mathrm{k}=0.00112$ \\
\hline Sun and Chakrabarty & $\mathrm{W}_{0}=0.341, \mathrm{Q}_{\mathrm{st}}{ }^{*}=3497.21, \mathrm{~m}=2.099, \alpha=9.00 \times 10^{-7}$ \\
\hline Mahle & $\mathrm{W}_{0}=0.35, \mathrm{~A}_{0}=0.89, \mathrm{~A}_{1}=-575, \mathrm{~B}=0.2$ \\
\hline \multicolumn{2}{|r|}{ Type-IV(b) (IRMOF-74-V-hex/nitrogen) } \\
\hline Universal & $\mathrm{W}_{0}=2.85, \varepsilon_{01}=852.32, \varepsilon_{02}=2364.60, \mathrm{~m}_{1}=138.23, \mathrm{~m}_{2}=608.42, \alpha_{1}=0.54, \alpha_{2}=0.46$ \\
\hline Mod BET & $\mathrm{V}_{\mathrm{m}}=0.21, \mathrm{C}=28, \mathrm{k}=0.8186$ \\
\hline Mahle & $\mathrm{W}_{0}=0.21, \mathrm{~A}_{0}=0.6, \mathrm{~A}_{1}=-650, \mathrm{~B}=0.075$ \\
\hline Mod Langmuir & $\mathrm{W}_{0}=80, \mathrm{z}=0.119, \beta=0.03622, \alpha=0.9941, \mathrm{n}_{1}=0.98, \phi_{\mathrm{m}}=3.22, \mathrm{~m}=0.478$ \\
\hline Tóth & $\mathrm{W}_{0}=2.9, \mathrm{~b}_{0}=0.0001041, \mathrm{Q}=4302.19, \mathrm{t}=1.3183$ \\
\hline \multicolumn{2}{|r|}{ Type-V (FAM-Z01/water) } \\
\hline Sun and Chakrabarty & $\mathrm{W}_{0}=0.2042, \mathrm{Q}_{\mathrm{st}}{ }^{*}=3027.841, \mathrm{~m}=4.893, \alpha=9 \times 10^{-7}$ \\
\hline Mod Langmuir & $\mathrm{W}_{0}=0.210, \mathrm{z}=2.955, \beta=0.60086, \alpha=0, \mathrm{n}_{1}=-1.5, \phi_{\mathrm{m}}=510.79, \mathrm{~m}=1.82$ \\
\hline
\end{tabular}


Table 2. Cont.

\begin{tabular}{|c|c|}
\hline Mahle & $\mathrm{W}_{0}=0.21, \mathrm{~A}_{0}=0.60, \mathrm{~A}_{1}=-650, \mathrm{~B}=0.075$ \\
\hline DA & $\mathrm{W}_{0}=0.212, \mathrm{E}=3985.785, \mathrm{n}=3.7075$ \\
\hline \multirow[t]{2}{*}{ Universal } & $\mathrm{W}_{0}=0.25, \varepsilon_{01}=3841.16, \varepsilon_{02}=0.01, \mathrm{~m}_{1}=530.08, \mathrm{~m}_{2}=2583.121, \alpha_{1}=0.67, \alpha_{2}=0.33$ \\
\hline & Type-VI (MgO/methane) \\
\hline Universal & $\begin{array}{c}\mathrm{W}_{0}=12, \varepsilon_{01}=3450, \varepsilon_{02}=1015.22, \varepsilon_{03}=235, \varepsilon_{04}=45, \mathrm{~m}_{1}=342, \mathrm{~m}_{2}=24.96, \mathrm{~m}_{3}=135.21 \\
\mathrm{~m}_{4}=93.44, \alpha_{1}=0.062, \alpha_{2}=0.05, \alpha_{3}=0.55, \alpha_{4}=0.40\end{array}$ \\
\hline Ben Yahia & $\begin{array}{c}\mathrm{n}_{1}=2.95, \mathrm{n}_{2}=19.52, \mathrm{n}_{3}=77.27, \mathrm{n}_{4}=23.26, \mathrm{~N}_{\mathrm{M} 1}=0.252, \mathrm{~N}_{\mathrm{M} 2}=0.036, \mathrm{~N}_{\mathrm{M} 3}=0.007, \mathrm{~N}_{\mathrm{M} 4}=0.071, \\
\mathrm{P}_{1}=0.70, \mathrm{P}_{2}=20.82, \mathrm{P}_{3}=36.06, \mathrm{P}_{4}=47.10\end{array}$ \\
\hline Mod. Langmuir & $\mathrm{W}_{0}=4, \mathrm{z}=4.38, \beta=0.044, \alpha=0.033, \mathrm{n}_{1}=-1.5, \phi_{\mathrm{m}}=44.77, \mathrm{~m}=0.683$ \\
\hline Mahle & $\mathrm{W}_{0}=4.457, \mathrm{~A}_{0}=2.013 \times 10^{-5}, \mathrm{~A}_{1}=62.92, \mathrm{~B}=0.0927$ \\
\hline D-A & $\mathrm{W}_{0}=4.012, \mathrm{E}=1219.71, \mathrm{n}=0.9$ \\
\hline
\end{tabular}

\subsection{Box-and-Whisker Plot}

Figure 3 shows the box-and-whisker plots using the observed RSMD of isotherm models for different types of isotherms. Each box plot demonstrates the distribution of RSMD estimates and their minimum, first quartile, median, third quartile, and maximum values. It is observed that in general, the distributions of RSMD estimations were positively skewed. However, the five-number summary of RSMD for the Tóth model was lower than other models for Type-I(a) and I(b) isotherms. Thus, the distribution of RSMD for the Tóth model was centered lower and less spread out compared to the candidate models. For type II isotherm the modified BET model is centered lower but spread out higher than other candidates. The results are similar in the case of Type-III isotherm where the GAB model also shows relatively lower values of median RSMD. The universal model is centered lower and less spread out than other models in the case of Type-IV(a) and IV(b) isotherms. In the case of Type- $\mathrm{V}$ isotherm, all models achieved a lower value of median and spread out less than the RSMD of the modified Langmuir model. The box plots for the Type-VI isotherm further show that the RSMD for Ben Yahia model was less spread out and centered lower than D-A and Universal models.

Based on Figure 3, it is therefore revealed that on average, the residuals of the Tóth model were relatively smaller and varied less compared to other models for Type-I(a). The finding was similar in the case of comparing the minimum, 1st quartile, 3rd quartile, maximum of Tóth model, and the other four candidates. Moreover, the Tóth model for Type-I(b), Mod BET model for Type-II, GAB model for Type-III, universal model for TypeIV(a) and Type-IV(b), Sun and Chakrabarty model for Type-V, and Ben Yahia model for Type-VI had the lower values of the five-number summary and dispersion compared to other models. Using the RSMD as a comparison criterion, these models were found better than other candidates in the respective isotherm cases. Table 3 presents the results of analysis of variance.

\subsection{Non-Parametric Test: Kruskal-Wallis Rank-Sum Test}

The non-parametric Kruskal-Wallis rank-sum test results containing degrees of freedom, chi-square statistic, and $p$-value are presented in Table 4 .

In the ANOVA tests, the null hypothesis states that the average RMSD of five candidate isotherm models is equal for each type. Because the $p$-value is less than the significance level of 0.01 , we can reject the null hypothesis for each type and conclude that some RMSD means of the models are different. So, in a particular type, all probable models are not equally likely, i.e., significantly differ. The null hypothesis of the non-parametric Kruskal-Wallis rank-sum test is similar to ANOVA, i.e., all candidate models for each type are equally fitted. The $p$-value is less than the significance level of 0.01 , so the hypothesis is rejected at $1 \%$ level of significance, which implies all probable candidate models have different errors 
meaning that they are significantly different. To identify the best-fitted isotherm model, pairwise Tukey HSD test and Wilcoxon rank-sum test have been performed, and the results are shown in Table 5.
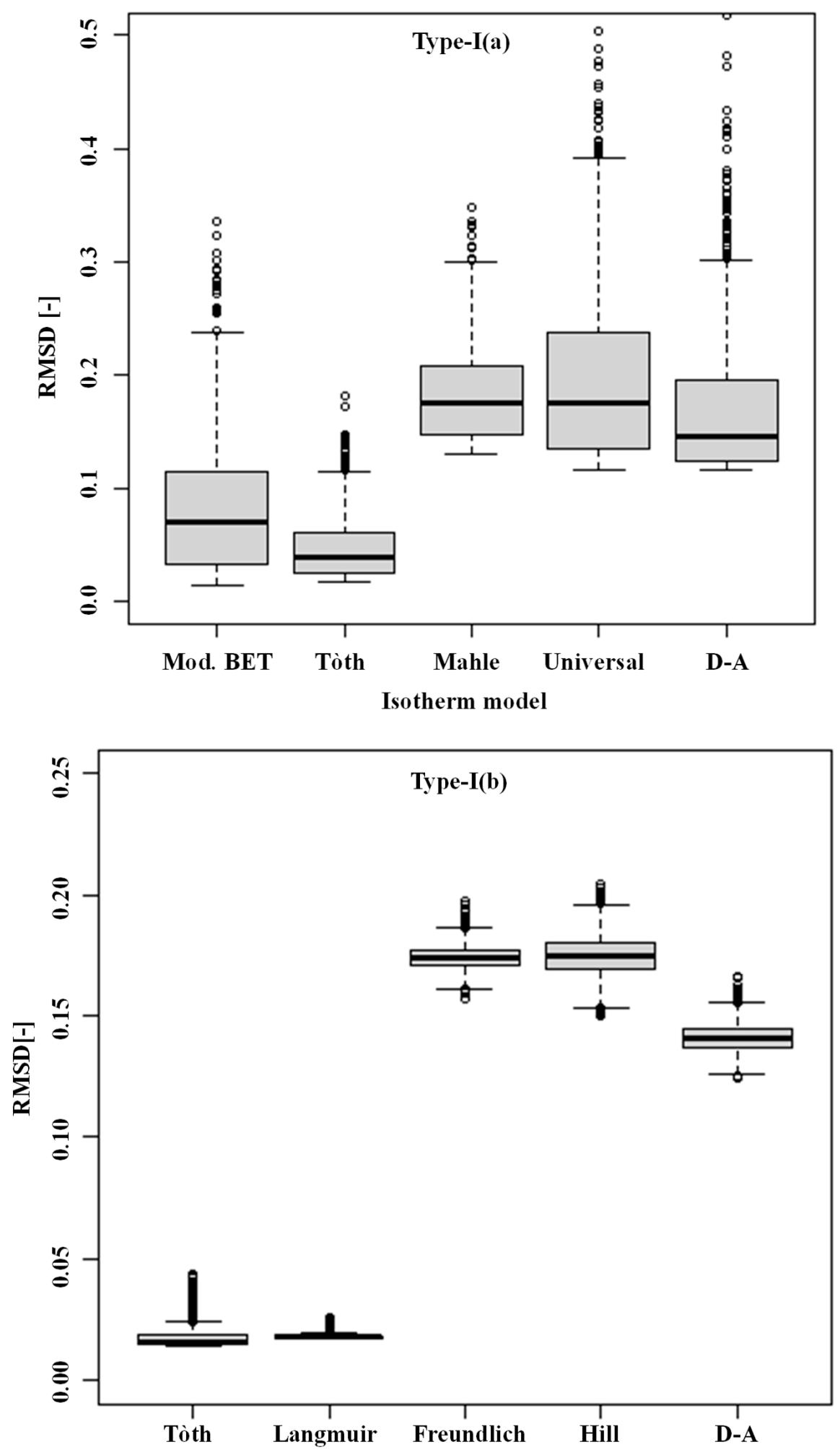

Figure 3. Cont. 

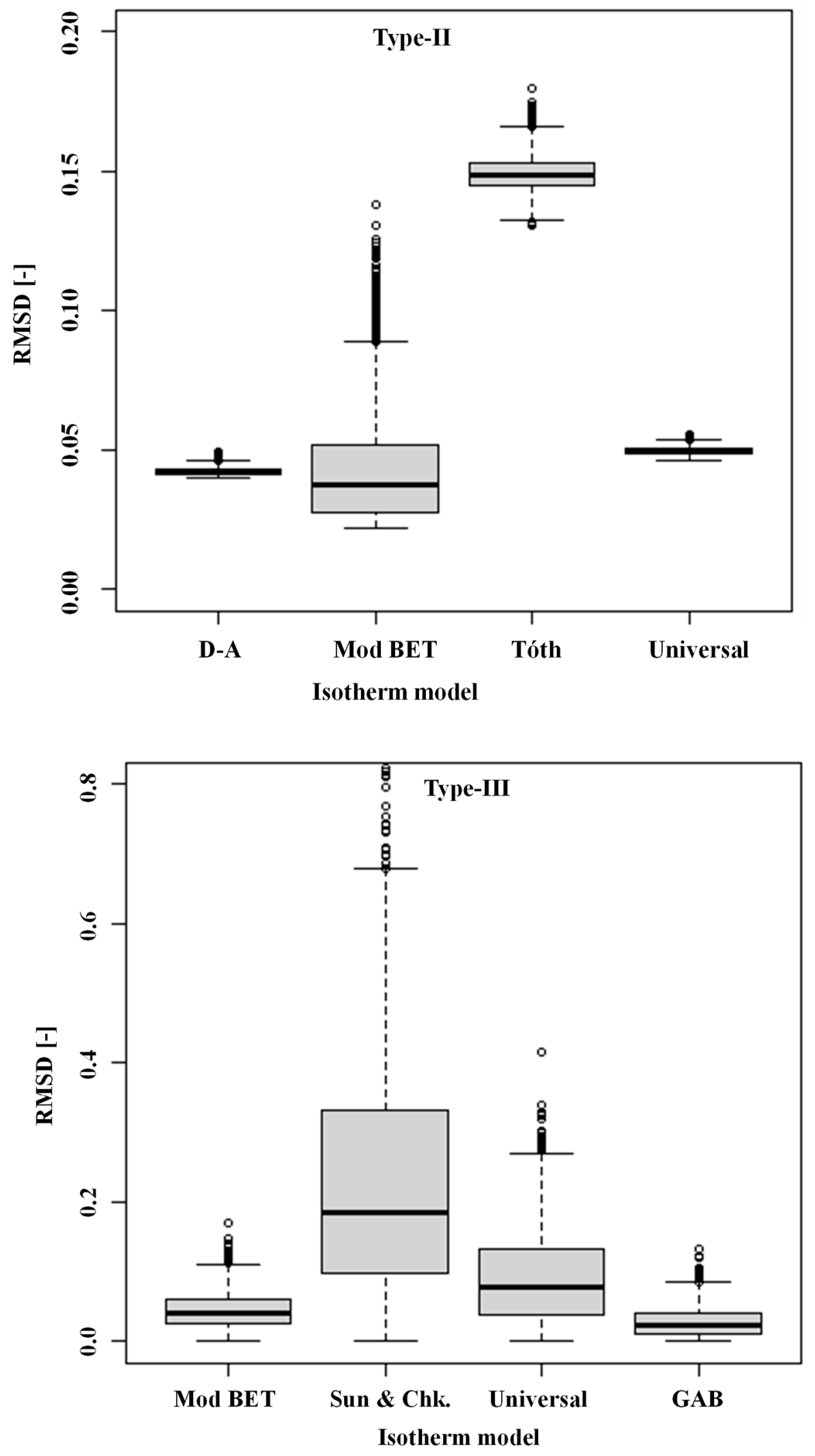

Figure 3. Cont. 

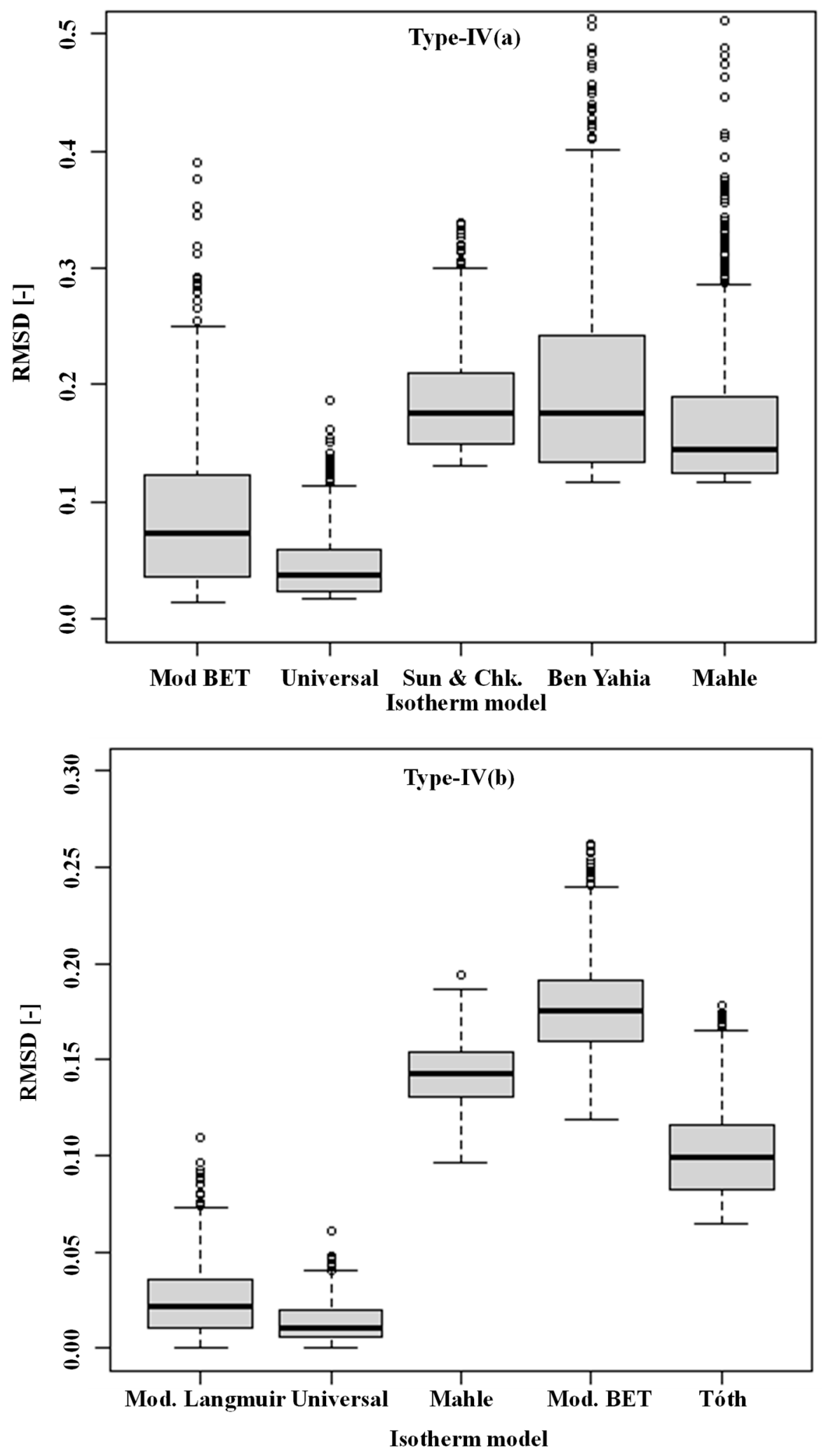

Figure 3. Cont. 

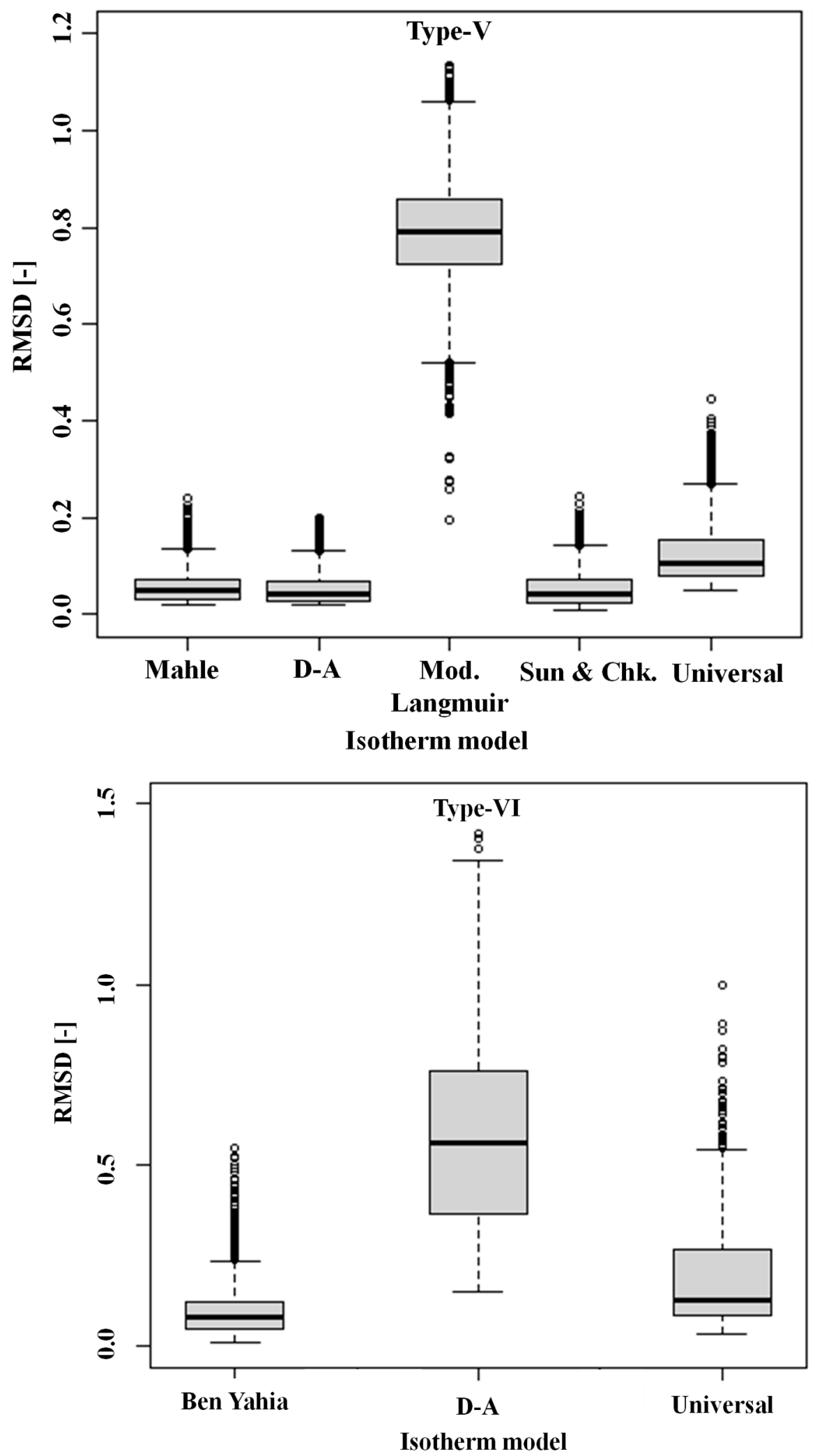

Figure 3. Box-and-whisker plots of the RMSD error ( $N=10,000$ simulated samples) were presented for all eight IUPAC classified isotherms. 
Table 3. Parametric Test: Analysis of Variance (ANOVA).

\begin{tabular}{cccccc}
\hline & DF & SS & Mean SS & F-Value & $p$-Value \\
\hline Type-I(a) & 4 & 261.72 & 65.43 & $2,532,683$ & $<2 \times 10^{-16 * * *}$ \\
\hline Type-I(b) & 4 & 25.23 & 6.308 & 8452 & $<2 \times 10^{-16 * * *}$ \\
\hline aType-II & 3 & 82.69 & 27.56 & 306,633 & $<2 \times 10^{-16 * * *}$ \\
\hline Type-III & 4 & 24.35 & 6.0875 & 2534 & $<2 \times 10^{-16 * * *}$ \\
\hline Type-IV(a) & 4 & 4896 & 1224 & 52,346 & $<2 \times 10^{-16 * * *}$ \\
\hline Type-IV(b) & 4 & 112.95 & 28.23 & 49,863 & $<2 \times 10^{-16 * * *}$ \\
\hline Type-V & 4 & 4184 & 1046 & 318,711 & $<2 \times 10^{-16 * * *}$ \\
\hline Type-VI & 4 & 3524.18 & 881.04 & 214,241 & $<2 \times 10^{-16 * * *}$ \\
\hline & & $* * *$ denote $1 \%$ level of significance. &
\end{tabular}

Table 4. Chi-square $\left(\chi^{2}\right)$ and $p$-value of Kruskal-Wallis rank-sum test results.

\begin{tabular}{cccc}
\hline Type & df & Chi-Square $\left(\chi^{2}\right)$ & $p$-Value \\
\hline Type-I(a) & 4 & 25,356 & $2.16 \times 10^{-13}$ \\
\hline Type-I(b) & 4 & 43,636 & $2.21 \times 10^{-14}$ \\
\hline Type-II & 3 & 28,296 & $2.22 \times 10^{-16}$ \\
\hline Type-III & 4 & 54,263 & $1.48 \times 10^{-11}$ \\
\hline Type-IV(a) & 4 & 35,421 & $2.25 \times 10^{-13}$ \\
\hline Type-IV(b) & 4 & 29,653 & $3.25 \times 10^{-15}$ \\
\hline Type-V & 4 & 24,806 & $2.20 \times 10^{-16}$ \\
\hline Type-VI & 4 & 35,412 & $2.22 \times 10^{-16}$ \\
\hline
\end{tabular}

Table 5. $p$-value of pairwise test results. Without parenthesis Tukey HSD and within parenthesis Wilcoxon rank-sum test.

\begin{tabular}{|c|c|c|c|c|}
\hline \multicolumn{5}{|c|}{ Type-I(a) } \\
\hline Model & Tóth & D-A & Mod BET & Universal \\
\hline D-A & $1.7 \times 10^{-7}\left(2.61 \times 10^{-8}\right)$ & - & - & - \\
\hline Mod BET & $1.6 \times 10^{-9}\left(1.96 \times 10^{-16}\right)$ & $1.8 \times 10^{-15}\left(2.21 \times 10^{-16}\right)$ & - & - \\
\hline Universal & $1.8 \times 10^{-7}\left(1.35 \times 10^{-16}\right)$ & $0.00360\left(2.31 \times 10^{-16}\right)$ & $2.2 \times 10^{-11}\left(2.36 \times 10^{-16}\right)$ & \\
\hline Mahle & $3.1 \times 10^{-4}\left(2.34 \times 10^{-16}\right)$ & $2.1 \times 10^{-12}\left(1.74 \times 10^{-16}\right)$ & $1.2 \times 10^{-5}\left(2.23 \times 10^{-16}\right)$ & $2.9 \times 10^{-7}\left(5.3 \times 10^{-16}\right)$ \\
\hline \multicolumn{5}{|c|}{ Type-I(b) } \\
\hline & Tóth & Langmuir & Freundlich & Hill \\
\hline Langmuir & $1.3 \times 10^{-11}\left(2 \times 10^{-16}\right)$ & - & - & - \\
\hline Freundlich & $2.3 \times 10^{-13}\left(2 \times 10^{-16}\right)$ & $2.5 \times 10^{-8}\left(2 \times 10^{-16}\right)$ & - & - \\
\hline Hill & $0.00021\left(2 \times 10^{-16}\right)$ & $4.2 \times 10^{-5}\left(2 \times 10^{-16}\right)$ & $1.8 \times 10^{-16}\left(2 \times 10^{-16}\right)$ & \\
\hline $\mathrm{D}-\mathrm{A}$ & $0.00032\left(2 \times 10^{-16}\right)$ & $2.3 \times 10^{-6}\left(2 \times 10^{-16}\right)$ & $3.2 \times 10^{-16}\left(2 \times 10^{-16}\right)$ & $2.6 \times 10^{-8}\left(2 \times 10^{-16}\right)$ \\
\hline \multicolumn{5}{|c|}{ Type-II } \\
\hline & Mod BET & Universal & D-A & \\
\hline Universal & $2.1 \times 10^{-15}\left(2 \times 10^{-16}\right)$ & - & - & \\
\hline D-A & $0.00898\left(2 \times 10^{-16}\right)$ & $1.6 \times 10^{-14}\left(2 \times 10^{-16}\right)$ & - & \\
\hline Tóth & $3.5 \times 10^{-12}\left(2 \times 10^{-16}\right)$ & $3.5 \times 10^{-15}\left(2 \times 10^{-16}\right)$ & $2.6 \times 10^{-11}\left(2 \times 10^{-16}\right)$ & \\
\hline
\end{tabular}


Table 5. Cont.

\begin{tabular}{|c|c|c|c|c|}
\hline \multicolumn{5}{|c|}{ Type-III } \\
\hline & GAB & Mod BET & Universal & D-A \\
\hline Mod BET & $1.9 \times 10^{-16}\left(2.10 \times 10^{-16}\right)$ & - & - & - \\
\hline Universal & $2.3 \times 10^{-14}\left(1.96 \times 10^{-16}\right)$ & $6.5 \times 10^{-14}\left(2.21 \times 10^{-16}\right)$ & - & - \\
\hline D-A & $5.9 \times 10^{-14}\left(1.35 \times 10^{-16}\right)$ & $2.3 \times 10^{-13}\left(2.31 \times 10^{-16}\right)$ & $3.1 \times 10^{-12}\left(2.36 \times 10^{-16}\right)$ & \\
\hline Sun and Chk & $2.6 \times 10^{-15}\left(2.34 \times 10^{-16}\right)$ & $3.5 \times 10^{-14}\left(1.74 \times 10^{-16}\right)$ & $2.8 \times 10^{-15}\left(2.23 \times 10^{-16}\right)$ & $2.4 \times 10^{-14}\left(5.3 \times 10^{-16}\right)$ \\
\hline \multicolumn{5}{|c|}{ Type-IV(a) } \\
\hline & Mod BET & Universal & Sun and Chk & Ben Yahia \\
\hline Universal & $2.3 \times 10^{-8}\left(2.10 \times 10^{-16}\right)$ & - & - & - \\
\hline Sun and Chk & $1.8 \times 10^{-9}\left(1.96 \times 10^{-16}\right)$ & $3.4 \times 10^{-10}\left(2.21 \times 10^{-16}\right)$ & - & - \\
\hline Ben Yahia & $3.6 \times 10^{-11}\left(1.35 \times 10^{-16}\right)$ & $2.4 \times 10^{-13}\left(2.31 \times 10^{-16}\right)$ & $2.7 \times 10^{-15}\left(2.36 \times 10^{-16}\right)$ & \\
\hline Mahle & $2.8 \times 10^{-8}\left(2.34 \times 10^{-16}\right)$ & $3.1 \times 10^{-10}\left(1.74 \times 10^{-16}\right)$ & $2.5 \times 10^{-10}\left(2.23 \times 10^{-16}\right)$ & $3.2 \times 10^{-16}\left(5.3 \times 10^{-16}\right)$ \\
\hline \multicolumn{5}{|c|}{ Type-IV(b) } \\
\hline & Mod Langmuir & Universal & Mahle & Mod BET \\
\hline Universal & $2.4 \times 10^{-15}\left(2.10 \times 10^{-16}\right)$ & - & - & - \\
\hline Mahle & $2.3 \times 10^{-14}\left(1.96 \times 10^{-16}\right)$ & $1.4 \times 10^{-15}\left(2.21 \times 10^{-16}\right)$ & - & - \\
\hline Mod BET & $2.1 \times 10^{-12}\left(1.35 \times 10^{-16}\right)$ & $1.9 \times 10^{-13}\left(2.31 \times 10^{-16}\right)$ & $2.2 \times 10^{-12}\left(2.36 \times 10^{-16}\right)$ & \\
\hline Tóth & $2.5 \times 10^{-14}\left(2.34 \times 10^{-16}\right)$ & $3.4 \times 10^{-11}\left(1.74 \times 10^{-16}\right)$ & $3.4 \times 10^{-16}\left(2.23 \times 10^{-16}\right)$ & $2.4 \times 10^{-16}\left(5.3 \times 10^{-16}\right)$ \\
\hline \multicolumn{5}{|c|}{ Type-V } \\
\hline & Mahle & D-A & Universal & Sun and Chk \\
\hline D-A & $2.1 \times 10^{-10}\left(7.98 \times 10^{-4}\right)$ & - & - & - \\
\hline Universal & $3.1 \times 10^{-12}\left(1.96 \times 10^{-16}\right)$ & $1.8 \times 10^{-9}\left(2.21 \times 10^{-16}\right)$ & - & - \\
\hline Sun and Chk & $2.7 \times 10^{-5}\left(1.13 \times 10^{-4}\right)$ & $0.7158(0.35142)$ & $2.3 \times 10^{-8}\left(2.36 \times 10^{-16}\right)$ & \\
\hline Mod Langmuir & $2.7 \times 10^{-14}\left(2.34 \times 10^{-16}\right)$ & $1.6 \times 10^{-12}\left(1.74 \times 10^{-16}\right)$ & $3.4 \times 10^{-15}\left(2.23 \times 10^{-16}\right)$ & $2.9 \times 10^{-13}\left(5.3 \times 10^{-16}\right)$ \\
\hline \multicolumn{5}{|c|}{ Type-VI } \\
\hline & Ben Yahia & Universal & D-A & Mod. Langmuir \\
\hline Universal & $2.2 \times 10^{-2}\left(2.10 \times 10^{-3}\right)$ & - & - & - \\
\hline D-A & $3.1 \times 10^{-12}\left(2.56 \times 10^{-12}\right)$ & $1.3 \times 10^{-12}\left(3.21 \times 10^{-12}\right)$ & - & - \\
\hline Mod. Langmuir & $3.6 \times 10^{-10}\left(2.51 \times 10^{-13}\right)$ & $3.9 \times 10^{-10}\left(5.23 \times 10^{-8}\right)$ & $3.5 \times 10^{-10}\left(7.65 \times 10^{-8}\right)$ & \\
\hline Mahle & $2.8 \times 10^{-9}\left(3.51 \times 10^{-11}\right)$ & $4.3 \times 10^{-7}\left(1.74 \times 10^{-12}\right)$ & $3.2 \times 10^{-12}\left(4.23 \times 10^{-11}\right)$ & $3.6 \times 10^{-14}\left(3.3 \times 10^{-13}\right)$ \\
\hline
\end{tabular}

The null hypothesis of pairwise Tukey HSD test and non-parametric Wilcoxon ranksum test state that each pair of models have equal RMSD means, indicating differences is zero. The $p$-values for these two tests are presented in Table 5 (Without parenthesis Tukey HSD and within parenthesis Wilcoxon rank-sum test). The $p$-value presented in Table 5 is very small, close to zero except for Sun and Chakrabarty vs. D-A of Type-V. So, all pairs of a specific type except Sun and Chakrabarty vs. D-A of Type-V are significantly different. So, based on the box-and-whisker plot and the overall and pairwise proportion test identified that Tóth for Type-I(a) and Type-I(b), modified BET for Type-II, GAB for Type-III, Universal model for Type-IV(a) and Type-IV(b), Sun and Chakraborty, and D-A models for Type-V, and Yahia et al. model for Type-VI are significantly optimum isotherm models.

\subsection{Physical Description with Merit and Demerits of the IUPAC Isotherm Model}

The Tóth model is determined to be the optimum for both Type-I(a) and Type-I(b) IUPAC isotherm. This model can be used to explain the monolayer adsorption process onto microporous adsorbents. Furthermore, the Tóth model well agrees in both Henry 
region and equilibrium at saturation. Whereas the Langmuir model only fits nicely in the low-pressure region, and the D-A model is well suited for the finite saturation region.

Type II isotherm is for monolayer and multilayer adsorption onto nonporous or macroporous adsorbents. Mod BET model is most suitable for all the pressure regions and this type of isotherm. Besides, D-A, Tóth, and universal models are close to the optimum model. The BET model fails to predict uptake around saturation pressure and can only be used to explain the multilayer adsorption process near saturation pressure.

The adsorbate-adsorbent interaction is rather weak in Type-III, and the adsorbed molecules cluster around the most favorable sites on the surface of a nonporous or macroporous material. The GAB model is most appropriate to explain this type of isotherm. GAB model is an upgrade of the modified BET model which considers all the assumptions of BET and modified BET model. Moreover, three other physical parameters are also included in this model that help to fit Type-III isotherms more accurately.

The interactions between the adsorbent and the adsorbate, as well as the interactions within the molecules in the condensed state, affect adsorption uptake onto the mesoporous adsorbent. The universal isotherm model, which includes two probability terms and an energy distribution parameter, has a high degree of agreement with Type-IV isotherms.

The Type- $\mathrm{V}$ isotherm is distinguished by its characteristic S-shaped form and the presence of a hysteresis loop. D-A, Tóth, and Langmuir models, in general, do not clarify the S-shaped isotherm within suitable error ranges. Sun and Chakrabarty model, on the other hand, considers (i) porous adsorbent materials structures, (ii) isosteric heat (Qst), and (iii) shape parameter $(m)$ of the isotherms, all of which helps to explain the S-shape pattern.

The reversible stepwise Type-VI isotherm is characterized by layer-by-layer adsorption over a highly uniform non-porous surface. The energetic part of the Ben Yahia model is assumed to be dominant, and the adsorption process is divided into four energies. This model takes into account the number of molecules per receptor site, the density of receptor sites, and the molar adsorption energy of gases that correspond well with Type-VI isotherms.

\subsection{Specific Cooling Effect (SCE)}

To validate this simulation study, two adsorption pairs, Maxsorb III/ethanol, and silica gel/water as Type-I(b) IUPAC isotherm, have been considered to calculate specific cooling effect (SCE) for cooling applications. The three most popular candidate models, namely, DA, Tóth, and Langmuir model as Type-I(b) isotherms, have been considered to calculate the specific cooling effect (SCE). Figure 4 shows the SCE for Maxsorb III/ethanol and Figure 5 depicts SCE for silica gel/water pair for different evaporating temperatures considering desorption temperatures from $40{ }^{\circ} \mathrm{C}$ to $100{ }^{\circ} \mathrm{C}$. Based on available experimental data, experimental SCE has been calculated and placed in Figures 4 and 5. Figure 4a indicates that the SCE, using the Tóth model, is closer to the experimental SCE compared to the D-A model for Maxsorb III/ethanol pair. Similarly, in Figure 4b, the SCE for Maxsorb III/ethanol pair using the Tóth model is closer to the experimental SCE relative to the Langmuir model. For silica gel/water pair, it is found from Figure 5a,b that the SCE of the Tóth model is closer to the SCE measured from experimental data. So, it is concluded that the Tóth model is more efficient compared to other models as Type-I(b) IUPAC classified adsorption isotherm. 

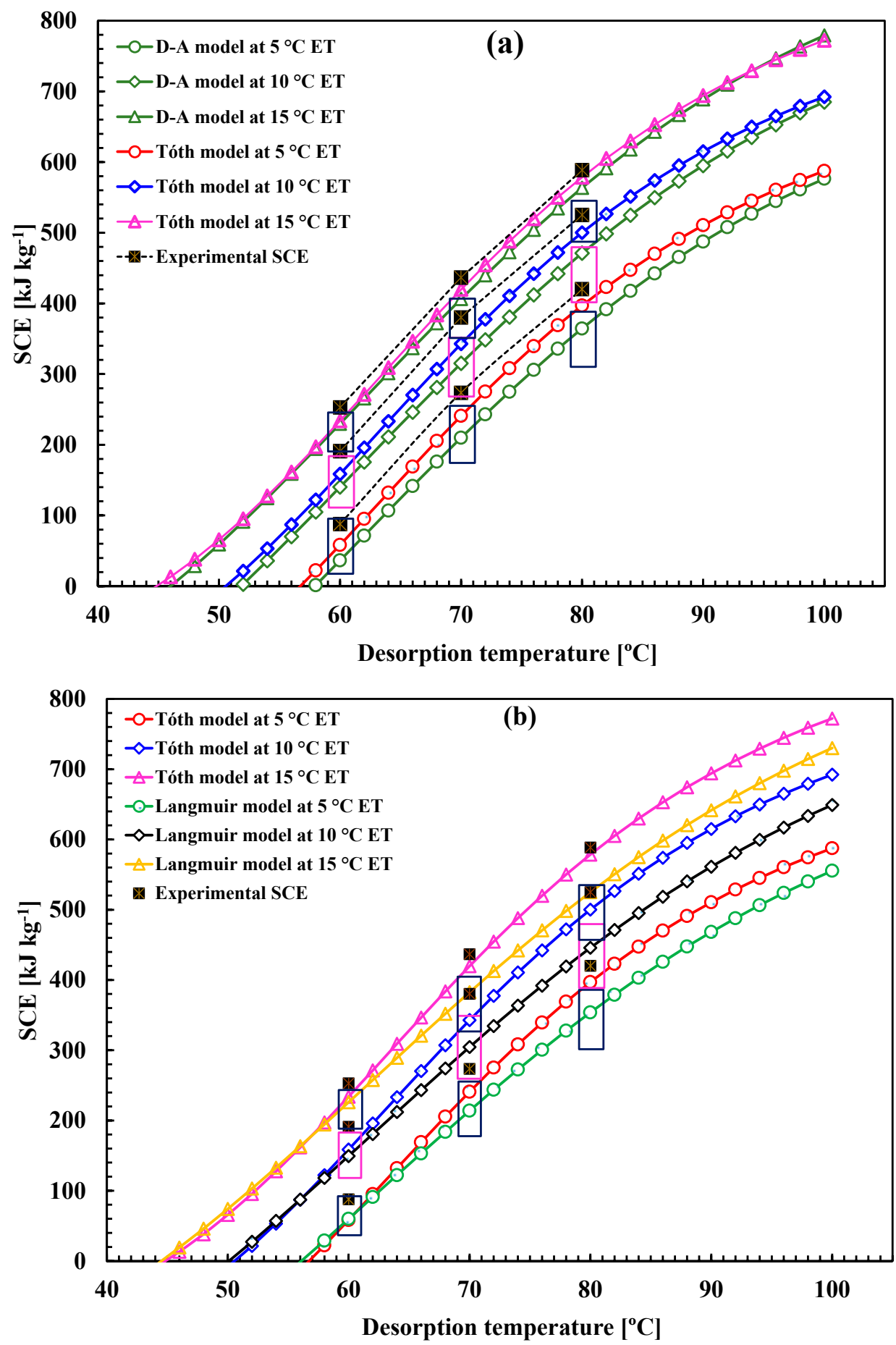

Figure 4. Experimental SCE comparisons with, (a) Tóth vs. D-A, and (b) Tóth vs. Langmuir model of Maxsorb III/ethanol adsorption pair for different evaporating temperatures. 

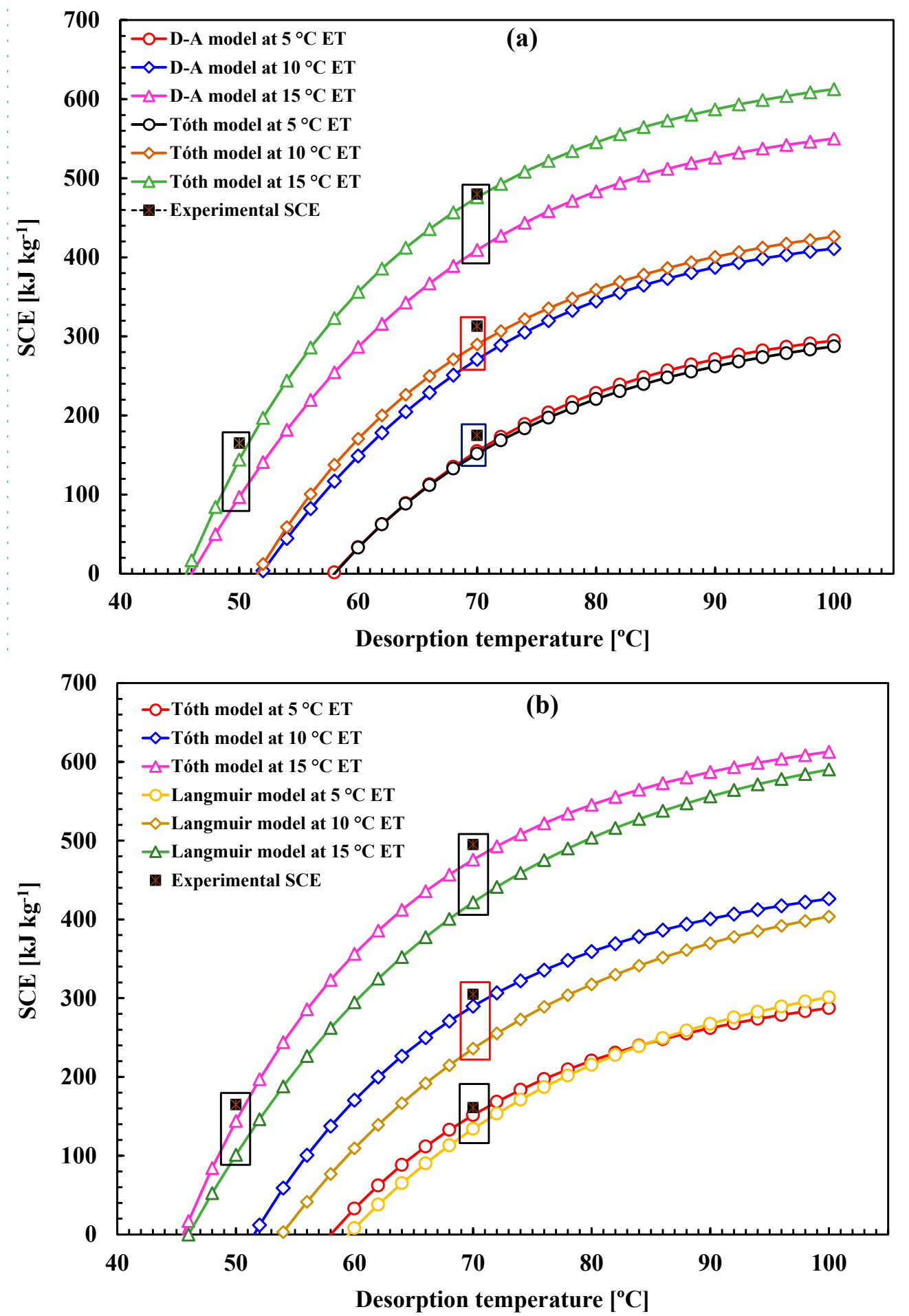

Figure 5. Experimental SCE comparisons with (a) Tóth vs. D-A models and (b) Tóth vs. Langmuir models of Silica gel/water adsorption pair for different evaporating temperatures.

\section{Conclusions}

Relevant adsorption isotherm pairs for all of the IUPAC types are chosen for analysis in this study. Sensitivity analysis of the parameters has been performed and error is minimized to identify the optimum model. The experimental isotherm data, extracted from literature, are then fitted with different isotherm models through the GRG non-linear optimization method. This study provides simulation-based optimum model selection, where $n=10,000$ samples were taken using multivariate normal distribution by varying 
parameters with a standard small range. Box-and-whisker plots are constructed by using 10,000 errors. Two overall mean test ANOVA and Kruskal-Wallis rank-sum test; two pairwise mean tests Tukey HSD and Wilcoxon rank-sum test confirms that Tòth for TypeI(a) and Type-I(b); modified BET for Type-II; GAB for Type-III; Universal for Type-IV(a) and Type-IV(b); Sun and Chakraborty and D-A for Type-V; and Ben Yahia for Type-VI are the significantly optimum models. The SCE measured by the Tòth model agrees well with the experimental SCE compared to the D-A and Langmuir models, indicating that the model suggested in this research is significantly optimum. Researchers can use the suggested optimum isotherms to execute a thorough investigation of adsorption cooling systems design.

Author Contributions: Conceptualization, M.M.R. and B.B.S.; Formal analysis, M.M.R., A.Z.S., M.A.I. and I.J.; Investigation, M.M.R., B.B.S. and A.P.; Methodology, M.M.R., I.J. and A.Z.S.; Software, M.M.R., A.Z.S. and I.J.; Supervision, B.B.S.; Validation, M.M.R., A.P. and M.A.I.; Writing-original draft, M.M.R. and A.Z.S.; Correction and revision of manuscript, M.M.R., A.P., M.A.I. and B.B.S. All authors have read and agreed to the published version of the manuscript.

Funding: This research did not receive any external funding.

Institutional Review Board Statement: Not applicable.

Informed Consent Statement: Not applicable.

Conflicts of Interest: The authors declare no conflict of interest.

\section{References}

1. Saha, B.B.; Koyama, S.; Kashiwagi, T.; Akisawa, A.; Ng, K.C.; Chua, H.T. Waste heat driven dual-mode, multi-stage, multi-bed regenerative adsorption system. Int. J. Refrig. 2003, 26, 749-757. [CrossRef]

2. Palomba, V.; Aprile, M.; Motta, M.; Vasta, S. Study of sorption systems for application on low-emission fishing vessels. Energy 2017, 134, 554-565. [CrossRef]

3. Ng, K.C.; Thu, K.; Saha, B.B.; Chakraborty, A. Study on a waste heat-driven adsorption cooling cum desalination cycle. Int. J. Refrig. 2012, 35, 685-693. [CrossRef]

4. Balaras, C.A.; Grossman, G.; Henning, H.-M.; Ferreira, C.A.I.; Podesser, E.; Wang, L.; Wiemken, E. Solar air conditioning in Europe-An overview. Renew. Sustain. Energy Rev. 2007, 11, 299-314. [CrossRef]

5. Saha, B.B.; El-Sharkawy, I.I.; Shahzad, M.W.; Thu, K.; Ang, L.; Ng, K.C. Fundamental and application aspects of adsorption cooling and desalination. Appl. Therm. Eng. 2016, 97, 68-76. [CrossRef]

6. Jaiswal, A.K.; Mitra, S.; Dutta, P.; Srinivasan, K.; Srinivasa Murthy, S. Influence of cycle time and collector area on solar driven adsorption chillers. Sol. Energy 2016, 136, 450-459. [CrossRef]

7. Islam, M.A.; Saha, B.B. TEWI Assessment of Conventional and Solar Powered Cooling Systems. In Solar Energy; Tyagi, H., Ed.; Springer Nature: Singapore, 2020; pp. 147-177. ISBN 9789811506758.

8. Muttakin, M.; Islam, M.A.; Malik, K.S.; Pahwa, D.; Saha, B.B. Study on optimized adsorption chiller employing various heat and mass recovery schemes. Int. J. Refrig. 2020, 126, 222-237. [CrossRef]

9. Thommes, M.; Kaneko, K.; Neimark, A.V.; Olivier, J.P.; Rodriguez-Reinoso, F.; Rouquerol, J.; Sing, K.S.W. Physisorption of gases, with special reference to the evaluation of surface area and pore size distribution (IUPAC Technical Report). Pure Appl. Chem. 2015, 87, 1051-1069. [CrossRef]

10. Rocky, K.A.; Pal, A.; Rupam, T.H.; Nasruddin; Saha, B.B. Zeolite-graphene composite adsorbents for next generation adsorption heat pumps. Microporous Mesoporous Mater. 2021, 313, 110839. [CrossRef]

11. Jahan, I.; Rupam, T.H.; Palash, M.L.; Rocky, K.A.; Saha, B.B. Energy efficient green synthesized MOF-801 for adsorption cooling applications. J. Mol. Liq. 2021, 117760. [CrossRef]

12. Rahman, M.M.; Muttakin, M.; Pal, A.; Shafiullah, A.Z.; Saha, B.B. A Statistical Approach to Determine Optimal Models for IUPAC-Classified Adsorption Isotherms. Energies 2019, 12, 4565. [CrossRef]

13. Muttakin, M.; Mitra, S.; Thu, K.; Ito, K.; Saha, B.B. Theoretical framework to evaluate minimum desorption temperature for IUPAC classified adsorption isotherms. Int. J. Heat Mass Transf. 2018, 122, 795-805. [CrossRef]

14. Pal, A.; Thu, K.; Mitra, S.; El-Sharkawy, I.I.; Saha, B.B.; Kil, H.S.; Yoon, S.H.; Miyawaki, J. Study on biomass derived activated carbons for adsorptive heat pump application. Int. J. Heat Mass Transf. 2017, 110, 7-19. [CrossRef]

15. Nebaghe, K.C.; El Boundati, Y.; Ziat, K.; Naji, A.; Rghioui, L.; Saidi, M. Comparison of linear and non-linear method for determination of optimum equilibrium isotherm for adsorption of copper(II) onto treated Martil sand. Fluid Phase Equilib. 2016, 430, 188-194. [CrossRef]

16. Ringot, D.; Lerzy, B.; Chaplain, K.; Bonhoure, J.P.; Auclair, E.; Larondelle, Y. In vitro biosorption of ochratoxin A on the yeast industry by-products: Comparison of isotherm models. Bioresour. Technol. 2007, 98, 1812-1821. [CrossRef] 
17. Do, D.D. Adsorption Analysis: Equilibria and Kinetics: (With CD Containing Computer Matlab Programs); Imperial College Press: London, UK, 1998; Volume 2, ISBN 978-1-78326-224-3.

18. Sun, B.; Chakraborty, A. Thermodynamic frameworks of adsorption kinetics modeling: Dynamic water uptakes on silica gel for adsorption cooling applications. Energy 2015, 84, 296-302. [CrossRef]

19. Kumar, K.V.; Porkodi, K. Relation between some two- and three-parameter isotherm models for the sorption of methylene blue onto lemon peel. J. Hazard. Mater. 2006, 138, 633-635. [CrossRef]

20. Karmaker, S.C.; Eljamal, O.; Saha, B.B. Response surface methodology for strontium removal process optimization from contaminated water using zeolite nanocomposites. Environ. Sci. Pollut. Res. 2021. [CrossRef]

21. Rahman, M.M.; Pal, A.; Uddin, K.; Thu, K.; Saha, B.B. Statistical Analysis of Optimized Isotherm Model for Maxsorb III/Ethanol and Silica Gel/Water Pairs. Evergreen 2018, 5, 1-12. [CrossRef]

22. Askalany, A.A.; Saha, B.B.; Uddin, K.; Miyzaki, T.; Koyama, S.; Srinivasan, K.; Ismail, I.M. Adsorption isotherms and heat of adsorption of difluoromethane on activated carbons. J. Chem. Eng. Data 2013, 58, 2828-2834. [CrossRef]

23. Amankwah, K.A.G.; Schwarz, J.A. A modified approach for estimating pseudo-vapor pressures in the application of the Dubinin-Astakhov equation. Carbon N. Y. 1995, 33, 1313-1319. [CrossRef]

24. Pal, A.; Uddin, K.; Rocky, K.A.; Thu, K.; Saha, B.B. $\mathrm{CO}_{2}$ adsorption onto activated carbon-graphene composite for cooling applications. Int. J. Refrig. 2019, 106, 558-569. [CrossRef]

25. Rocky, K.A.; Pal, A.; Moniruzzaman, M.; Saha, B.B. Adsorption characteristics and thermodynamic property fields of polymerized ionic liquid and polyvinyl alcohol based composite $/ \mathrm{CO}_{2}$ pairs. J. Mol. Liq. 2019, 294, 111555. [CrossRef]

26. Allen, S.J.; Gan, Q.; Matthews, R.; Johnson, P.A. Comparison of optimised isotherm models for basic dye adsorption by kudzu. Bioresour. Technol. 2003, 88, 143-152. [CrossRef]

27. Berdenova, B.; Pal, A.; Saha, B.B.; Kaltayev, A. Non-isothermal pore change model predicting $\mathrm{CO}_{2}$ adsorption onto consolidated activated carbon. Int. J. Heat Mass Transf. 2021, 177, 121480. [CrossRef]

28. Foo, K.Y.; Hameed, B.H. Insights into the modeling of adsorption isotherm systems. Chem. Eng. J. 2010, 156, 2-10. [CrossRef]

29. Rahman, M.M.; Karmaker, S.C.; Pal, A.; Eljamal, O.; Saha, B.B. Statistical techniques for the optimization of cesium removal from aqueous solutions onto iron-based nanoparticle-zeolite composites. Environ. Sci. Pollut. Res. 2020, 28, 12918-12931. [CrossRef]

30. Mahle, J.J. An adsorption equilibrium model for Type 5 isotherms. Carbon N. Y. 2002, 40, 2753-2759. [CrossRef]

31. Peleg, M. Assessment of a semi-empirical four parameter general model for sigmoid moisture sorption isotherm. J. Food Process Eng. 1993, 16, 21-37. [CrossRef]

32. Maroulis, Z.B.; Tsami, E.; Marinos-Kouris, D.; Saravacos, G.D. Application of the GAB model to the moisture sorption isotherms for dried fruits. J. Food Eng. 1988, 7, 63-78. [CrossRef]

33. McMinn, W.A.M.; Magee, T.R.A. Thermodynamic properties of moisture sorption of potato. J. Food Eng. 2003, 60, 157-165. [CrossRef]

34. Kayal, S.; Baichuan, S.; Saha, B.B. Adsorption characteristics of AQSOA zeolites and water for adsorption chillers. Int. J. Heat Mass Transf. 2016, 92, 1120-1127. [CrossRef]

35. Zou, J.; Rezaee, R. A prediction model for methane adsorption capacity in shale gas reservoirs. Energies 2019, 12, 280. [CrossRef]

36. Sun, B.; Chakraborty, A. Thermodynamic formalism of water uptakes on solid porous adsorbents for adsorption cooling applications. Appl. Phys. Lett. 2014, 104, 201901. [CrossRef]

37. Yahia, M.B.; Khalfaoui, M.; Hachicha, M.A.; Lamine, A.B.; Torkia, Y.B.; Knani, S. Models for Type VI Adsorption Isotherms from a Statistical Mechanical Formulation. Adsorpt. Sci. Technol. 2013, 31, 341-357. [CrossRef]

38. Aouaini, F.; Knani, S.; Ben Yahia, M.; Ben Lamine, A. Statistical physics studies of multilayer adsorption isotherm in food materials and pore size distribution. Phys. A Stat. Mech. Its Appl. 2015, 432, 373-390. [CrossRef]

39. Ng, K.C.; Burhan, M.; Shahzad, M.W.; Ismail, A. Bin A Universal Isotherm Model to Capture Adsorption Uptake and Energy Distribution of Porous Heterogeneous Surface. Sci. Rep. 2017, 7, 1-11. [CrossRef]

40. Saha, B.B.; Jribi, S.; Koyama, S.; El-Sharkawy, I.I. Carbon dioxide adsorption isotherms on activated carbons. J. Chem. Eng. Data 2011, 56, 1974-1981. [CrossRef]

41. Vardeman, S.B.; Walpole, R.E.; Myers, R.H.; Miller, I.; Freund, J.E. Probability and Statistics for Engineers and Scientists. Probability and Statistics for Engineers; Pearson Education Inc.: Upper Saddle River, NJ, USA, 1986; Volume 81, ISBN 0132047675.

42. Hogg, R.V.; Tanis, E.A.; Zimmerman, D.L. Probability and Statistical Interference; Pearson Education Inc.: Upper Saddle River, NJ, USA, 2003; ISBN 9780133936544.

43. Saville, D.J. Multiple comparison procedures: The practical solution. Am. Stat. 1990, 44, 174-180. [CrossRef]

44. Altman, D.G.; Bland, J.M. Practical statistics for medical research. BMJ 1995, 310, 170. [CrossRef]

45. Siegel, S. Nonparametric Statistics. Am. Stat. 1957, 11, 13-19. [CrossRef]

46. Liu, Y.; Chen, W. A SAS macro for testing differences among three or more independent groups using Kruskal-Wallis and Nemenyi tests. J. Huazhong Univ. Sci. Technol.-Med. Sci. 2012, 32, 130-134. [CrossRef] [PubMed]

47. Bergmann, R.; Ludbrook, J. Different outcomes of the wilcoxon-mann-whitney test from different statistics packages. Am. Stat. 2000, 54, 72-77. [CrossRef]

48. Uddin, K.; El-Sharkawy, I.I.; Miyazaki, T.; Baran Saha, B.; Koyama, S. Thermodynamic analysis of adsorption cooling cycle using ethanol-surface treated maxsorb III Pairs. Evergreen 2014, 1, 25-31. [CrossRef] 